\title{
Translation initiation complex formation in the crenarchaeon Sulfolobus solfataricus
}

\author{
DAVID HASENÖHRL, ${ }^{1}$ ATTILIO FABBRETTI, ${ }^{2}$ PAOLA LONDEI, $^{\mathbf{3}}$ ClAUDIO O. GUALERZI, $^{2}$ and UDO BLÄSI ${ }^{1}$ \\ ${ }^{1}$ Max F. Perutz Laboratories, Department of Microbiology, Immunobiology and Genetics, University of Vienna, 1030 Vienna, Austria \\ ${ }^{2}$ Laboratory of Genetics, Department of Biology, Molecular Cell Biology and Animal Biology, University of Camerino, 62032 Camerino \\ (Macerata), Italy \\ ${ }^{3}$ Department of Cellular Biotechnology and Hematology, University of Rome La Sapienza, 00161 Rome, Italy
}

\begin{abstract}
The function of initiation factors in and the sequence of events during translation initiation have been intensively studied in Bacteria and Eukaryotes, whereas in Archaea knowledge on these functions/processes is limited. By employing chemical probing, we show that translation initiation factor alF1 of the model crenarchaeon Sulfolobus solfataricus binds to the same area on the ribosome as the bacterial and eukaryal orthologs. Fluorescence energy transfer assays (FRET) showed that alF1, like its eukaryotic and bacterial orthologs, has a fidelity function in translation initiation complex formation, and that both alF1 and alF1 $\mathrm{A}$ exert a synergistic effect in stimulating ribosomal association of the Met-tRNAi ${ }^{\text {Met }}$ binding factor a/eIF2. However, as in Eukaryotes their effect on a/elF2 binding appears to be indirect. Moreover, FRET was used to analyze for the first time the sequence of events toward translation initiation complex formation in an archaeal model system. These studies suggested that a/eIF2-GTP binds first to the ribosome and then recruits Met-tRNAi ${ }^{\text {Met }}$, which appears to comply with the operational mode of bacterial IF2, and deviates from the shuttle function of the eukaryotic counterpart eIF2. Thus, despite the resemblance of elF2 and a/eIF2, recruitment of initiator tRNA to the ribosome is mechanistically different in Pro- and Eukaryotes.
\end{abstract}

Keywords: Archaea; Sulfolobus solfataricus; translation initiation; alF1; a/elF2

\section{INTRODUCTION}

Protein synthesis in Prokaryotes starts with the interaction of initiator fMet-tRNA $\mathrm{fet}, \mathrm{mRNA}$, and the small (30S) ribosomal subunit. The two ligands can bind randomly to the $30 \mathrm{~S}$ ribosomal subunit without initially interacting with each other, yielding a $30 \mathrm{~S}$ pre-initiation complex (Gualerzi and Pon 1990). A rate-limiting conformational change, which is kinetically controlled by all three initiation factors IF1, IF2, and IF3, converts the 30S pre-initiation complex into a 30S initiation complex (Gualerzi and Pon 1990; Gualerzi et al. 2001). During this transition the initiation codon of the mRNA moves from an initial "standby" site to the P-decoding site, where it base-pairs with the anticodon of $\mathrm{fMet}_{\mathrm{tRNAi}}^{\mathrm{Met}}$ ( $\mathrm{La}$ Teana et al. 1995; Yusupova et al. 2006; Kaminishi et al. 2007). The trans-

Reprint requests to: David Hasenöhrl, Max F. Perutz Laboratories, Department of Microbiology, Immunobiology and Genetics, University of Vienna, Dr. Bohrgasse 9, 1030 Vienna, Austria; e-mail: david.hasenoehrl@ univie.ac.at; fax: ++43-1-4277-9546; or Udo Bläsi, Max F. Perutz Laboratories, Department of Microbiology, Immunobiology and Genetics, University of Vienna, Dr. Bohrgasse 9, 1030 Vienna, Austria; e-mail: udo. blaesi@univie.ac.at; fax: ++43-1-4277-9546.

Article published online ahead of print. Article and publication date are at http://www.rnajournal.org/cgi/doi/10.1261/rna.1662609. lation initiation factors IF1, IF2, and IF3 have different roles in facilitating $30 \mathrm{~S}$ initiation complex formation (Laursen et al. 2005). IF3 affects both the on and off rates of $\mathrm{fMet}^{-\mathrm{tRNAi}} \mathrm{i}_{\mathrm{f}}^{\mathrm{Met}}$ binding and introduces a translational bias that impedes translational starts from noncanonical initiation complexes (Gualerzi and Pon 1990; Gualerzi et al. 2001). Recent studies have shown that IF3 release from the ribosome occurs during formation of the $70 \mathrm{~S}$ initiation complex, i.e., during joining of the 50S subunit with the 30 S initiation complex (Milon et al. 2008). IF2 has a complementary role to that of IF3, selectively promoting ribosomal binding of $\mathrm{fMet}-\mathrm{tRNAi} \mathrm{i}_{\mathrm{fet}}^{\mathrm{Met}}$ by increasing its onrate (Gualerzi et al. 2001). It has been a matter of debate whether fMet-tRNAi $\mathrm{i}_{\mathrm{f}}^{\mathrm{Met}}$ binds to $30 \mathrm{~S}$ subunits as part of a binary complex with IF2 (Mayer et al. 2003), or whether fMet-tRNAi $i_{\mathrm{f}}^{\text {Met }}$ is recruited by 30 -bound IF2 (Boelens and Gualerzi 2002). Recent fluorescence energy transfer assays (FRET) argue for the latter mode of action (M Carotti and CO Gualerzi, unpubl.). IF1 was shown to bind to the A-site of the $30 \mathrm{~S}$ subunit, thereby preventing premature A-site binding of elongator tRNA (Moazed et al. 1995).

Translation initiation in Eukaryotes starts with the assembly of the eIF2-GTP•Met-tRNAi ${ }^{\text {Met }}$ ternary complex (Richter and Lipmann 1970). After its formation, the 
ternary complex binds to the $40 \mathrm{~S}$ ribosomal subunit. This binding is facilitated by the initiation factors eIF1, eIF1A, and eIF3, resulting in the $43 \mathrm{~S}$ complex. On the other hand the eIF4F complex assembles on the $5^{\prime}$-cap of the mRNA. eIF4F in conjunction with eIF3 and the poly(A) binding protein bound to the $3^{\prime}$-tail of the mRNA then by virtue of protein-protein interactions loads the mRNA onto the $43 \mathrm{~S}$ complex (for recent reviews, see Kapp and Lorsch 2004; Acker and Lorsch 2008; Sonenberg and Hinnebusch 2009). The $43 \mathrm{~S}$ complex then scans along the mRNA in $5^{\prime} \rightarrow 3^{\prime}$ direction in search for the start codon. Cryoelectron microscopy studies suggested that both eIF1 and eIF1A maintain the initiating ribosome in an "open" scanning competent conformation until the start codon is located, and start-codon/anti-codon base-pairing has been established (Passmore et al. 2007). As a result of a conformational change in the complex eIF1 is released (Maag et al. 2005; Cheung et al. 2007). The release of eIF1 could free the C terminus of eIF1A for interactions with eIF5, which stabilizes the closed state of the complex (Maag et al. 2006). The final step in translation initiation includes joining of the $60 \mathrm{~S}$ ribosomal subunit to the $43 \mathrm{~S}$ pre-initiation complex. The factor eIF5B facilitates subunit joining, whereby GTP hydrolysis is not required for subunit joining per se, but for the release of eIF5B after subunit joining has occurred (Pestova et al. 2000; Shin et al. 2002).

Archaea possess more translation initiation factors than Bacteria, but lack some of the eukaryotic ones, including those present in the cap complex, eIF4F, eIF3, and the GDP-GTP exchange factor for eIF2. The best-studied translation initiation factor is a/eIF2, which is pivotal for Met-tRNAi ${ }^{\text {Met }}$ binding to the ribosome (Yatime et al. 2004; Pedulla et al. 2005). Several 3D structures are available for a/eIF2, providing information on the general shape of the trimeric factor and Met-tRNAi ${ }^{\mathrm{Met}}$ binding (Yatime et al. 2006; Nikonov et al. 2007; Yatime et al. 2007). Recent studies showed that aIF1 promotes formation of the 30S•a/eIF2-GTP•Met-tRNAi ${ }^{\text {Met }}$ complex (Hasenöhrl et al. 2006). In addition to its Met-tRNAi ${ }^{\text {Met }}$ binding function, a/eIF2, in particular the a/eIF2 $\gamma$-subunit, was shown to bind with high affinity to the triphosphorylated $5^{\prime}$ end $\left(5^{\prime}-\mathrm{P}_{3}\right.$-end) of mRNA, leading to protection from $5^{\prime} \rightarrow 3^{\prime}$ mRNA decay. In addition, this study indicated that the ratio between the a/eIF2 $\gamma$ levels and 30S subunits increase under starvation conditions, which was paralleled by an increased in vivo stability of the $5^{\prime}$ segment of Sulfolobus solfataricus 2508 mRNA (Hasenöhrl et al. 2008). Another archaeal factor with an assigned function is aIF5B. The protein functions as a ribosome-dependent GTPase, which is important for translation of both leaderless and canonical mRNAs (Maone et al. 2007). In S. solfataricus and other Crenarchaeota, mRNAs are often bicistronic. The first cistron frequently encodes a leaderless mRNA, at which the $5^{\prime}$-terminal codon either serves as the start codon or the start codon is preceded by only a few nucleotides. In con- trast, internal cistrons are generally preceded by a ShineDalgarno (SD) sequence (Tolstrup et al. 2000).

In contrast to bacterial (McCutcheon et al. 1999; Carter et al. 2001; Dallas and Noller 2001; Marzi et al. 2003) and eukaryal factors (Lomakin et al. 2003; Fraser et al. 2007; Unbehaun et al. 2007), the localization of archaeal translation initiation factors on the ribosome is unknown. Here, we present the first probing data for S. solfataricus aIF1 on the $30 \mathrm{~S}$ subunit, provide evidence for a fidelity function of aIF1, and show that this factor in conjunction with aIF1A stimulates binding of a/eIF2 to the $30 \mathrm{~S}$ ribosomal subunit. Moreover, we address the question of the sequence of events during assembly of the translation initiation complex in $S$. solfataricus by scrutinizing whether a ternary a/eIF2-GTP•Met-tRNAi ${ }^{\text {Met }}$ complex-like in Eukaryotesshuttles Met-tRNAi ${ }^{\text {Met }}$ to the $30 \mathrm{~S}$ ribosome, or whether a/eIF2 binds first to $30 \mathrm{~S}$ and then recruits Met-tRNAi ${ }^{\mathrm{Met}}$.

\section{RESULTS}

\section{Localization of alF1 on the $S$. solfataricus $30 \mathrm{~S}$ ribosomal subunit}

Hydroxyl radical probing was used to study the interaction between $S$. solfataricus translation initiation factor aIF1 and the 30 S ribosomal subunit. S. solfataricus $30 \mathrm{~S}$ subunits and aIF1 contained in two separate syringes were mixed in a quench flow apparatus. After an incubation period of $2 \mathrm{sec}, \mathrm{Fe}(\mathrm{II})$-EDTA was added, and the cleavage reaction was allowed to proceed for $20-30 \mathrm{msec}$ before being quenched. The cleavage pattern of the entire 16S rRNA was analyzed in the absence or presence of aIF1 by primer extension using primers covering the whole 16S rRNA. As shown in Figure 1, aIF1 protected nucleotides 658/659 (Fig. 1A,C) and 749/750 (Fig. 1B,D) in helices 23 and 24, respectively, both of which are located at the subunit interface of the $30 \mathrm{~S}$ ribosomal subunit (Spahn et al. 2001). Chemical probing experiments in the presence of both aIF1 and aIF1A revealed footprints in helices 23 and 24 indistinguishable from those obtained in the presence of only aIF1 (data not shown). The presence of both, aIF1 and aIF1A, protected additionally nucleotides 1011-1012 in helix 34 (Supplemental Fig. S1). However, chemical probing with aIF1A alone, unlike aIF1, did not affect the hydroxyl radical cleavage pattern of 16S rRNA (data not shown). We therefore consider the protection observed in helix 34 by aIF1/aIF1A to result from conformational changes upon binding of aIF1A or both factors rather than from a direct shielding of this region by aIF1A.

According to these data, aIF1 binds to the 30 S ribosomal subunit at an analogous position as the eukaryotic ortholog eIF1 (Lomakin et al. 2003) and the presumed functional homolog IF3 (Dallas and Noller 2001). The similar topographical localization indicated that these factors could have similar functions, i.e., a role in (1) avoidance of 
A

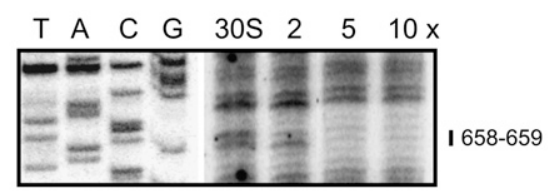

B

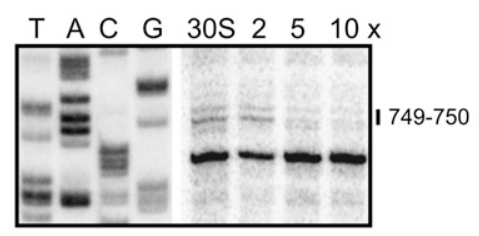

C

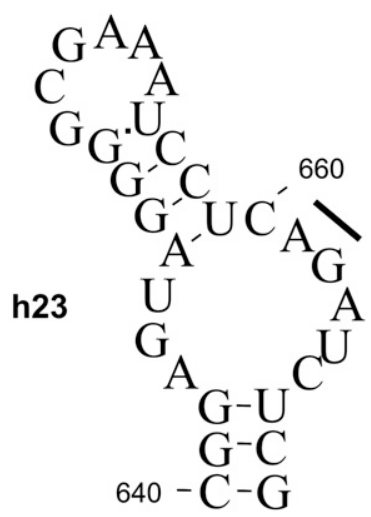

D

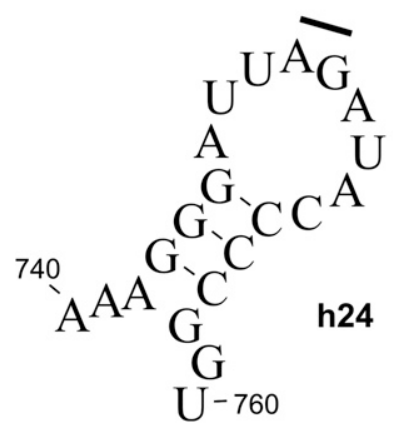

FIGURE 1. Hydroxyl radical probing of $16 \mathrm{~S}$ rRNA in 30S/aIF1 complexes. $(A, B)$ Primer extension analysis of helices $23(A)$ and $24(B)$ in 16S rRNA in 30S/aIF1 complexes upon hydroxyl radical probing. The individual lanes are indicated: $16 \mathrm{~S}$ rRNA sequencing (T, A, C, and $\mathrm{G}), 30 \mathrm{~S}$ modified in the absence of the factor (30S) or in the presence of the stoichiometric excess of aIF1 $(2 \times, 5 \times$, and $10 \times$, as indicated). $(C, D)$ Elements of helices 23 and 24 of $16 \mathrm{~S}$ rRNA with protected sites shown by bars.

premature subunit joining during translation initiation, (2) acceleration of on and off kinetics of translation initiation complex formation, (3) increasing the ribosome affinity for other translational components, and (4) ensuring a fidelity function in translation initiation start-codon selection.

\section{alF1 discriminates against a noncanonical start codon}

To assess whether aIF1 acts as a fidelity factor in translation initiation, mRNA binding to the $30 \mathrm{~S}$ subunit was analyzed by fast kinetics employing a fluorescence energy transfer (FRET) assay. The FRET signal resulting from binding of fluorescein-labeled mRNA to a pre-assembled complex consisting of $30 \mathrm{~S}$, fluorescently labeled a/eIF2 ${ }_{565}$, GTP, Met-tRNAi ${ }^{\mathrm{Met}}$, and $\mathrm{aIF1A}$ was measured in the presence and absence of aIF1, and as a function of the nature of the initiation triplet present on the mRNA. Two types of mRNA-oligonucleotides were used, one containing the canonical AUG triplet (AUG-mRNA F $_{\text {) }}$ and the other the noncanonical AUU triplet (AUU-mRNA ${ }_{\mathrm{F}}$ ). As shown in Figure $2 \mathrm{~A}$, in the presence of aIF1 the binding of the AUG-mRNA $A_{F}$ to the ribosome was increased, while that of the AUU-mRNA $A_{F}$ was strongly diminished. This discrimination by aIF1 was observed only in the presence of MettRNAi ${ }^{\mathrm{Met}}$, while in its absence aIF1 had no effect on binding of either AUGmRNA $_{\mathrm{F}}$ or the AUU-mRNAF (Fig. 2B). This finding indicated that the fidelity function of aIF1 depends on the startcodon/anti-codon interaction.

\section{alF1 and alF1A stimulate binding of a/elF2 to the ribosome}

It has been recently shown that aIF1 stimulates translation in $S$. solfataricus (Hasenöhrl et al. 2006). To test whether this results from a stimulation of ribosomal binding of a/eIF2 by aIF1 and/or aIF1A, we took advantage of the fluorescence spectral change which occurs upon binding of fluorescently labeled a/eIF $2_{565}$ to $S$. solfataricus 30 S ribosomal subunits or to $30 \mathrm{~S}$ particles pre-incubated with aIF1 and/or aIF1A. Initial experiments revealed that the kinetics of binding to $30 \mathrm{~S}$ subunits were identical for a/eIF2 ${ }_{565}$, a/eIF2 ${ }_{565}$-GTP, and a/eIF2 ${ }_{565}$-GTP•Met-tRNAi ${ }^{\text {Met }}$ (data not shown). As shown in Figure 3A, binding of a/eIF $2_{565}$ to $30 \mathrm{~S}$ subunits pre-incubated with aIF1 (blue trace), aIF1A (green trace), or both aIF1 and aIF1A (red trace) was faster when compared with binding of a/eIF $2_{565}$ to the $30 \mathrm{~S}$ ribosomal subunit in the absence of aIF1/aIF1A (orange trace). A two-exponential fit was used to analyze the data. The $k_{\text {on }}$ values for binding of a/eIF2 to 30S ribosomes and to the 30S•aIF1•aIF1A complex were calculated with $12 \pm 0.5 \mu \mathrm{M}^{-1} \mathrm{sec}^{-1}$ and $67 \pm 3 \mu \mathrm{M}^{-1} \mathrm{sec}^{-1}$, respectively (Fig. 3B). The $y$-axis intercept yielded dissociation rate constants $\left(k_{\text {off }}\right)$ of $1.07 \pm$ $0.4 \mathrm{sec}^{-1}$ for the 30S•aIF1•aIF1A complex and of $0.76 \pm$ $0.01 \mathrm{sec}^{-1}$ for $30 \mathrm{~S}$ ribosomes. The equilibrium binding constant for binding of a/eIF2 resulted in a $K_{\mathrm{d}}=0.015 \pm$ $0.007 \mu \mathrm{M}$ for the 30S•aIF1•aIF1A complex and $0.06 \pm$ $0.005 \mu \mathrm{M}$ for the $30 \mathrm{~S}$ subunit alone (Fig. 3B). The concentration-dependent analysis of $k_{\text {app1 } 1}$ and $k_{\text {app2 }}$ indicated that the fast reaction $\left(k_{\mathrm{app} 2}\right)$ reflects binding and the slow reaction $\left(k_{\text {app } 1}\right)$ the adjustment of binding.

Far-Western blotting and co-immunoprecipitation did not reveal any direct interaction between aIF1 and a/eIF2 in 
A
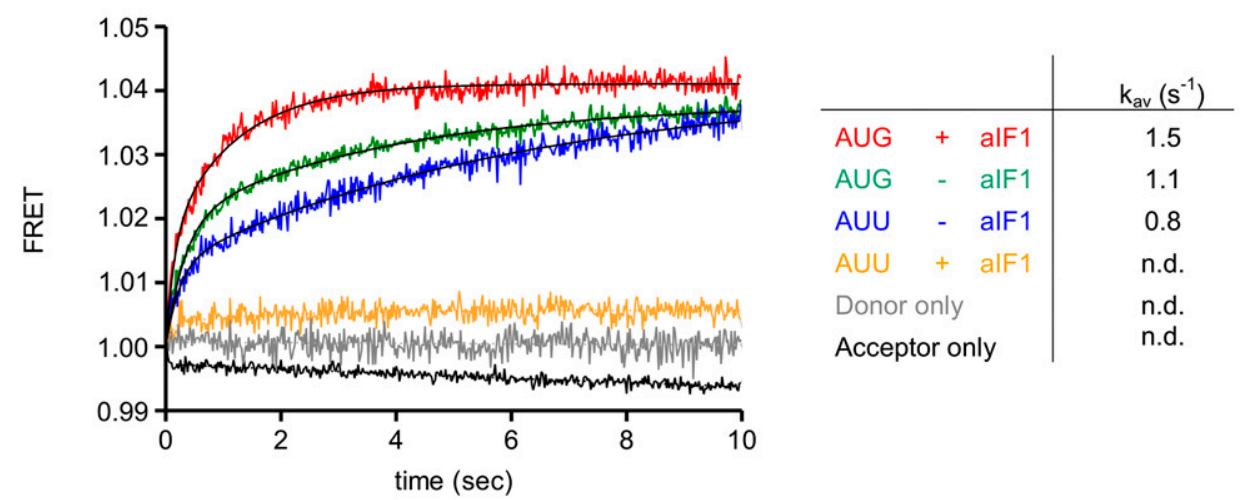

B

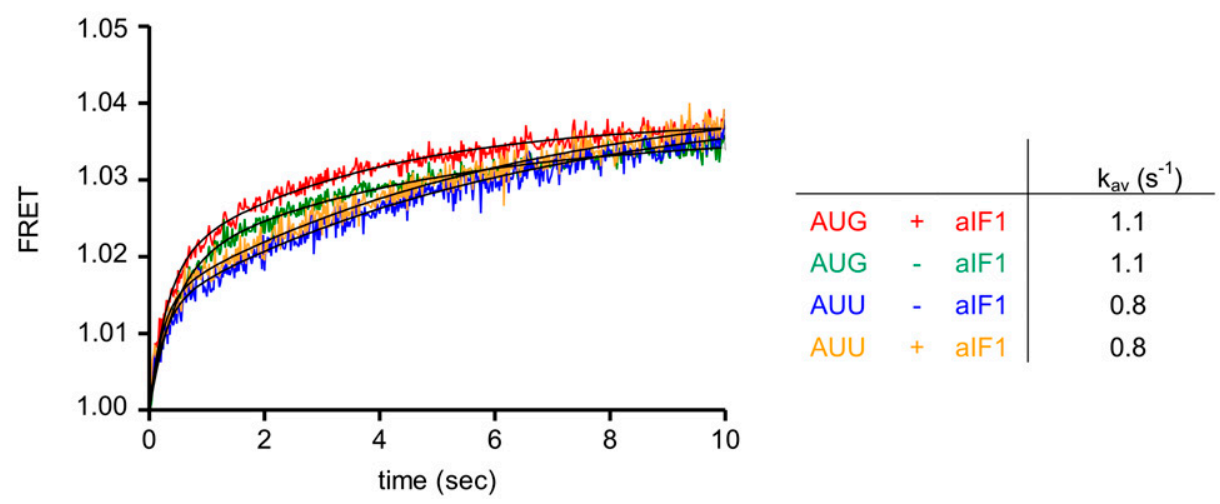

FIGURE 2. Discrimination by aIF1 against a non-AUG start codon. (A) AUG-mRNA binding to $30 \mathrm{~S} \bullet a I F 1 \mathrm{~A} \bullet \mathrm{a} / \mathrm{eIF} 2_{565}-\mathrm{GTP} \bullet \mathrm{Met}-\mathrm{tRNAi}{ }^{\mathrm{Met}}$ in the absence (green trace) and presence (red trace) of aIF1. AUU-mRNA binding to $30 \mathrm{~S} \bullet a I F 1 A \bullet a / e I F 2_{565}-G T P \bullet M e t-t R N A i^{\text {Met }}$ in the absence (blue trace) and presence (orange trace) of aIF1. Control measurements were performed with unlabeled AUG-mRNA and labeled a/eIF2 ${ }_{565}$ (black trace, acceptor only) or with labeled AUG-mRNA $A_{F}$ and unlabeled a/eIF2 (gray trace, donor only). (B) AUG-mRNAF binding to 30S•aIF1A $\bullet$ a/ eIF2 ${ }_{565}$-GTP in the absence of Met-tRNAi ${ }^{\text {Met }}$ and in the presence (red trace) or absence (green trace) of aIF1. AUU-mRNA ${ }_{\mathrm{F}}$ binding to $30 \mathrm{~S} \bullet \mathrm{aIF} 1 \mathrm{~A} \bullet \mathrm{a} / \mathrm{eIF} 2_{565}$-GTP in the absence (blue trace) and presence (orange trace) of aIF1. The charts in $A$ and $B$ show the $k_{\mathrm{av}}$ values determined as described in Materials and Methods.

solution (Supplemental Fig. S2). In addition, single cysteine mutants of aIF1 (the cysteine at position 6 was substituted by alanine, leaving only one cysteine at position 14) and aIF1A (the cysteines at postion 25 and 40 were substituted by alanines, leaving only the cysteine at position 78) were labeled with Atto488. In the absence of S. solfataricus 30S ribosomal subunits no FRET signals were obtained between $\mathrm{aIF}_{488}$ or aIF1 $\mathrm{A}_{488}$ and a/eIF2 $2_{565}$, respectively (data not shown). Taken together, these data did not favor a direct stimulation of a/eIF2 binding to the 30 S ribosomal subunit by aIF1 and/or aIF1A.

\section{Order of events toward formation of the archaeal translation-initiation complex}

It has been recently observed that the free a/eIF2 trimer has a higher affinity for the $5^{\prime}$ triphosphate end $\left(5^{\prime}-\mathrm{P}_{3}\right)$ of mRNAs than for Met-tRNAi ${ }^{\text {Met }}$ (Hasenöhrl et al. 2008). Since binding of Met-tRNAi ${ }^{\mathrm{Met}}$ to $S$. solfataricus ribosome strictly requires the presence of a/eIF2 (Yatime et al. 2004;
Pedulla et al. 2005), this finding was at first glance difficult to reconcile with a Met-tRNAi ${ }^{\text {Met }}$ shuttling function of a/eIF2, as known for the eukaryotic factor eIF2 (Kapp and Lorsch 2004). In fact, a preferential binding of a/eIF2 to mRNA rather than to Met-tRNAi ${ }^{\mathrm{Met}}$ would be expected to interfere with translation initiation. However, competition experiments revealed that, while increasing concentrations of $5^{\prime}-\mathrm{P}_{3}$-RNA released Met-tRNAi ${ }^{\text {Met }}$ from an a/eIF2GTP•Met-tRNAi ${ }^{\text {Met }}$ complex, they hardly competed away the Met-tRNAi ${ }^{\text {Met }}$ bound to a 30S•a/eIF2-GTP complex. Moreover, when $5^{\prime}-\mathrm{P}_{3}$-mRNA was added to a 30S•aIF $1 \bullet$ a/ eIF2-GTP•Met-tRNAi ${ }^{\text {Met }}$ complex, Met-tRNAi ${ }^{\text {Met }}$ was not released (Hasenöhrl et al. 2008). Thus, reasoning that the apparent competition between the $5^{\prime}-\mathrm{P}_{3}$-RNA and MettRNAi $^{\text {Met }}$ for a/eIF2 would be alleviated if (1) a/eIF2-GTP would associate faster with $30 \mathrm{~S}$ subunits than with $5^{\prime}-\mathrm{P}_{3^{-}}$ RNA, and (2) 30S-bound a/eIF2-GTP would have a higher affinity for Met-tRNAi ${ }^{\text {Met }}$ than for $5^{\prime}-\mathrm{P}_{3}$-RNA, we determined the $k_{\text {on }}$ of a/eIF2 ${ }_{565}$-GTP for Met-tRNAi ${ }^{\text {Met }}$ and for the $5^{\prime}-\mathrm{P}_{3}$-end of mRNA. As a/eIF2 binding was 
A

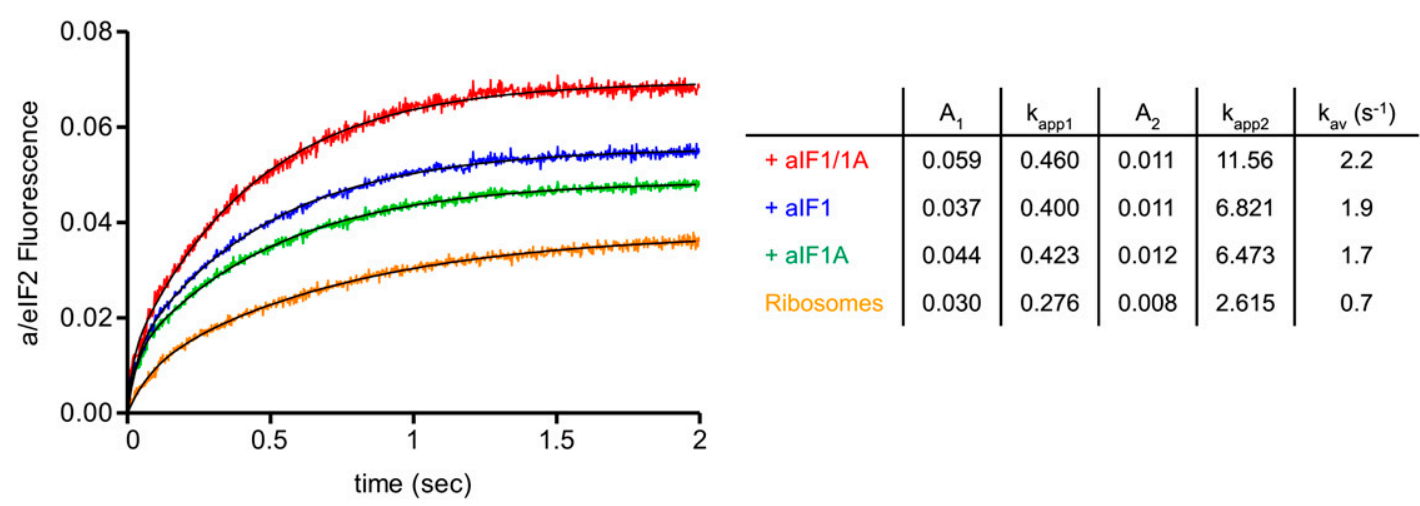

B

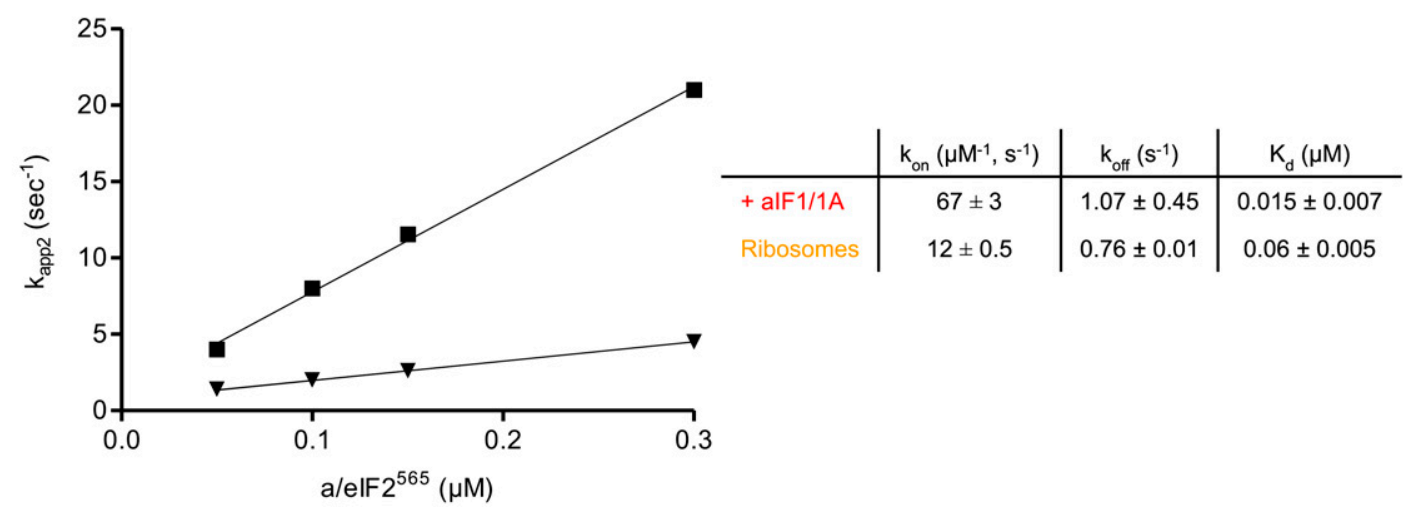

FIGURE 3. aIF1 and aIF1A stimulate a/eIF2 binding to $S$. solfataricus $30 \mathrm{~S}$ ribosomal subunits. (A) a/eIF $2_{565}$ binding to $30 \mathrm{~S}$ ribosomal subunits (orange trace) and in the presence of 30S-bound aIF1A (green trace), aIF1 (blue trace), and aIF1/aIF1A (red trace), respectively. The chart shows the $\mathrm{A}_{1}, k_{\mathrm{app} 1}, \mathrm{~A}_{2}, k_{\mathrm{app} 2}$, and $k_{\mathrm{av}}$ values determined by a two-exponential fitting as described in Materials and Methods. (B) The $k_{\mathrm{on}}$ values for a/eIF2 565 binding to $30 \mathrm{~S} \bullet \mathrm{aIF} 1 \bullet$ aIF1A complexes $(\boldsymbol{\nabla})$ and to $30 \mathrm{~S}$ subunits $(\boldsymbol{\nabla})$ were determined by titration of the respective $k_{\text {app2 } 2}$ values obtained at different concentrations of a/eIF2 $2_{565}$. The chart shows the $k_{\mathrm{on}}, k_{\mathrm{off}}$, and $K_{\mathrm{d}}$ values determined as described in Materials and Methods.

observed to be dependent only on the $5^{\prime}-\mathrm{P}_{3}$-end of mRNA but not on its primary sequence, we used the $5^{\prime}$ segment of 2508sh RNA, which had served as a model mRNA in our previous studies (Hasenöhrl et al. 2008). Flouresceinlabeled $2508 s h\left(2508 s h_{\mathrm{F}}\right)$ RNA or Met-tRNAi $\mathrm{F}_{\mathrm{Fet}}^{\mathrm{Me}}$ were incubated with increasing concentrations of a/eIF $2_{565}$, and the $K_{\mathrm{d}}$ values were determined from the $k_{\text {on }}$ and $k_{\text {off }}$ values derived from the FRET signal(s) between the two ligands. When compared with the $K_{\mathrm{d}}$ of a/eIF2-GTP for the 30S•aIF1•aIF1A complex $(0.015 \pm 0.007 \mu \mathrm{M}$, Fig. 3B), the $K_{\mathrm{d}}$ values of a/eIF2 ${ }_{565}-\mathrm{GTP}$ for $2508 s h_{\mathrm{F}}$ RNA $\left(K_{\mathrm{d}}=\right.$ $0.042 \pm 0.01 \mu \mathrm{M})$ and Met-tRNAi ${ }_{\mathrm{F}}^{\text {Met }}\left(K_{\mathrm{d}}=0.15 \pm 0.01 \mu \mathrm{M}\right)$ were approximately threefold and 10-fold lower (Fig. 4A), respectively. This indicated that a/eIF2-GTP binds preferentially to $30 \mathrm{~S}$ ribosomes rather than to the $5^{\prime}-\mathrm{P}_{3}$-end of mRNA or to Met-tRNAi ${ }^{\text {Met }}$. Furthermore, we asked whether 30S-bound a/eIF2 ${ }_{565}$-GTP displays a higher affinity for Met-tRNAi ${ }^{\text {Met }}$ when compared to the $5^{\prime}-\mathrm{P}_{3}$ terminus of 2508 sh RNA. As shown in Figure 4 B, the $K_{d}$ determined for Met-tRNAi ${ }^{\text {Met }}$ binding to a $30 \mathrm{~S} \cdot \mathrm{aIF} 1 \bullet \mathrm{aIF} 1 \mathrm{~A} \bullet \mathrm{a} / \mathrm{eIF} 2_{565^{-}}$ GTP complex was $0.004 \pm 0.002 \mu \mathrm{M}$, whereas binding of $5^{\prime}-\mathrm{P}_{3}-2508$ sh RNA to this ribosome complex was negligible. In addition, binding of Met-tRNAi ${ }^{\text {Met }}$ to a 30S•a/eIF2-GTP complex was hardly affected by the presence of $2508 \mathrm{sh}$ RNA (Fig. 4C). Clearly, these in vitro studies do not account for eventual changes in the concentration of components of the translational apparatus which may occur during different stages of growth. Despite this drawback, these in vitro studies provide the first indication that in the archaeon S. solfataricus 30S-bound a/eIF2 recruits MettRNAi $^{\mathrm{Met}}$.

\section{DISCUSSION}

We have shown that the archaeal translation initiation factor aIF1 contacts helices 23 and 24 of its homologous 16S rRNA (Fig. 1), thereby occupying a position near inter-subunit bridges of the 30S subunit (Spahn et al. 2001; Yusupov et al. 
A

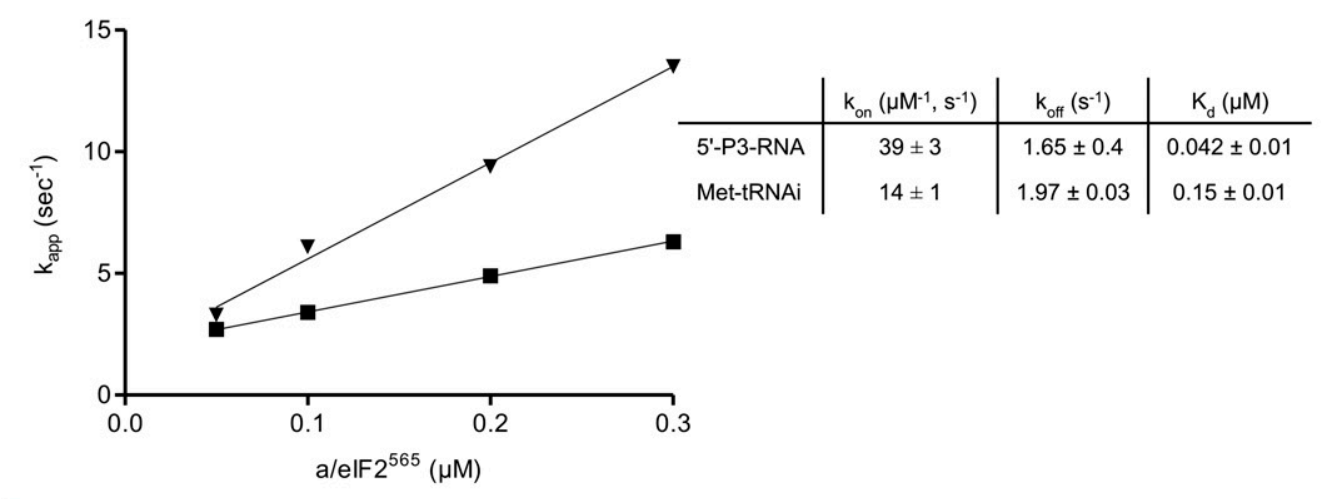

B

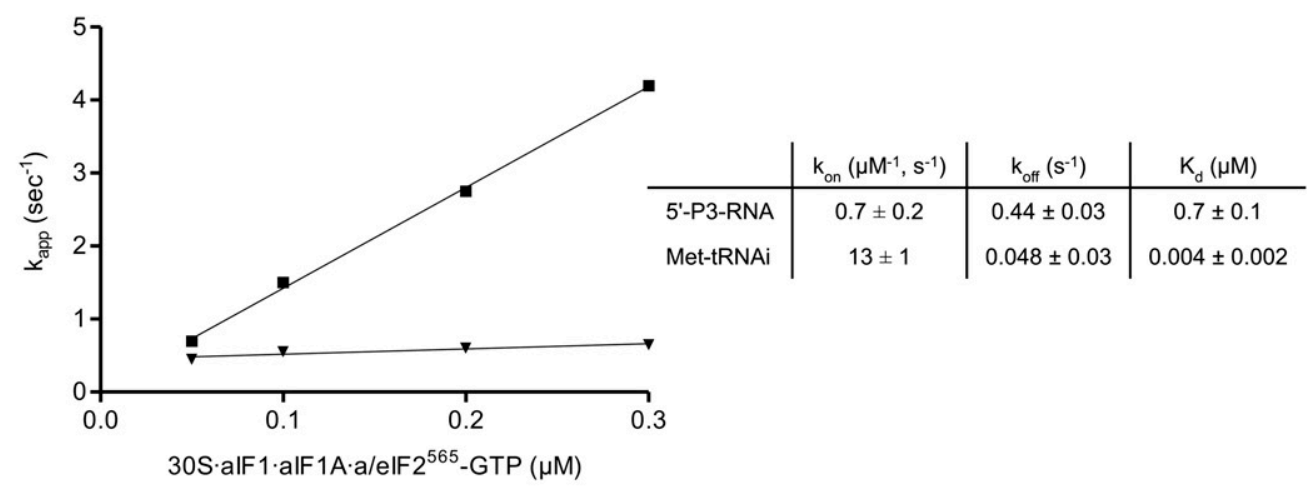

C

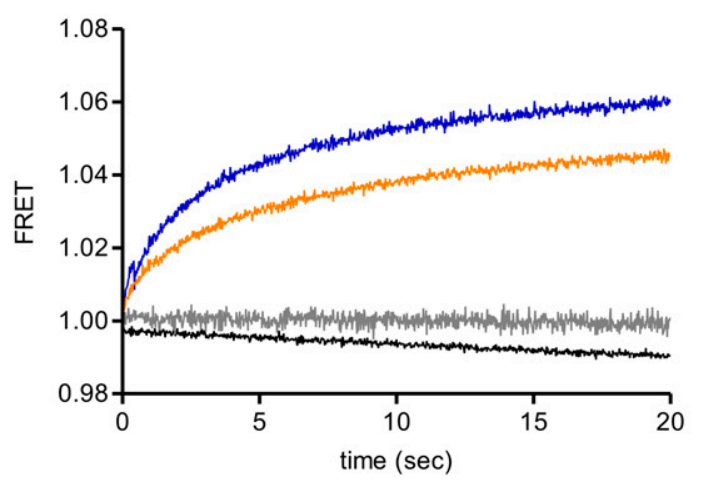

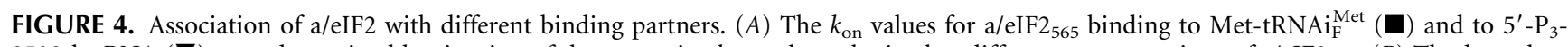
$2508 \mathrm{sh}_{\mathrm{F}}$ RNA $(\boldsymbol{\nabla})$ were determined by titration of the respective $k_{\text {app }}$ values obtained at different concentrations of a/eIF2 565 . $(B)$ The $k_{\text {on }}$ values for Met-tRNAi Met $(\boldsymbol{\nabla})$ and $5^{\prime}-\mathrm{P}_{3}-2508 \mathrm{sh}_{\mathrm{F}} \mathrm{RNA}(\boldsymbol{\nabla})$ binding to a $30 \mathrm{~S} \bullet$ aIF1 $\bullet$ aIF1A $\bullet$ a/eIF2 ${ }_{565}$-GTP complex were determined by titration of the respective $k_{\text {app }}$ values obtained at different concentrations of the $30 \mathrm{~S} \bullet$ aIF $1 \bullet a I F 1 A \bullet a / e I F 2_{565}$-GTP complex. The charts in $A$ and $B$ show the $k_{\text {on }}, k_{\text {off }}$, and $K_{\mathrm{d}}$ values determined as described in Materials and Methods. (C) 30S•a/eIF2 binding to Met-tRNAi Met (blue trace) and to equimolar concentrations (see Materials and Methods) of Met-tRNAi ${ }_{F}^{\mathrm{Met}}$ and $5^{\prime}-\mathrm{P}_{3}-2508$ sh RNA (orange trace). Control measurements were performed with unlabeled AUG-mRNA and labeled a/eIF2 ${ }_{565}$ (black trace, acceptor only) or with labeled Met-tRNAi Met and unlabeled a/eIF2 (gray trace, donor only). As donor and acceptor were stable under the experimental conditions, the downward slope of the two control curves may reflect photobleaching.

2001). This topographical localization is equivalent to that found for eukaryal eIF1 and bacterial IF3 (Dallas and Noller 2001; Lomakin et al. 2003), suggesting that aIF1, like its eukaryal and bacterial counterparts, may prevent premature subunit joining during translation initiation (Subramanian and Davis 1970; Petrelli et al. 2001; Lomakin et al. 2003). In the presence of both, aIF1 and aIF1A, additional protection was observed in helix 34 (Supplemental Fig. S1), possibly 
resulting from conformational changes induced by this factor(s). Structural changes in helix 34 of eukaryotic $18 \mathrm{~S}$ rRNA were also observed upon binding of eIF1 and eIF1A to the $40 \mathrm{~S}$ subunit (Passmore et al. 2007). These observations may indicate that the functions in translation initiation of these archaeal and eukaryal factors are similar.

Recent experiments indicated that aIF1 stimulates translation initiation complex formation by accelerating binding of a/eIF2 to the $30 \mathrm{~S}$ ribosomal subunit (Hasenöhrl et al. 2006). Here, we extended these experiments by showing that aIF1 and aIF1A act in concert to stimulate a/eIF2 binding to the ribosome (Fig. 3). However, using different in vitro methods, we were unable to demonstrate a direct interaction between aIF1 or aIF1A with a/eIF2. It is worth mentioning that eukaryotic eIF1 binds to a domain of the eIF2 $\beta$-subunit (Singh et al. 2004), which is absent in its archaeal homolog a/eIF2 $\beta$ (Pedulla et al. 2005). Thus, it seems reasonable to speculate that aIF1/aIF1A facilitate a/eIF2 binding to the $30 \mathrm{~S}$ subunit by inducing structural changes in the ribosomal subunit. Similarly, eIF1 and eIF1A were shown to stabilize conformational changes that apparently accelerate eIF2 $\bullet$ GTP•Met-tRNAi ${ }^{\text {Met }}$ binding to 40 S subunits (Passmore et al. 2007).

We have shown that aIF1, like bacterial IF3 and its eukaryal ortholog eIF1, which discriminate against noncanonical start codons (Hartz et al. 1990; Lomakin et al. 2003), can inhibit ribosome binding of a short mRNA containing a noncanonical AUU start codon (Fig. 2A). Given its topographical localization on the $30 \mathrm{~S}$ subunit (Fig. 1), it is unlikely that aIF1-like eIF1 (Lomakin et al. 2003) and bacterial IF3 (Gualerzi et al. 2001)—inspects directly the nature of the codon. Instead, as the codonanticodon interaction is apparently required for the discrimination against the mRNA containing the noncanonical initiation codon (Fig. 2B), it is likely that aIF1 monitors structural changes that occur upon base-pairing of the start codon with the anti-codon of initiator tRNA. Taken together our results suggest that some functions of aIF1, e.g., proofreading and the acceleration of the translation initiation complex formation, are analogous to that of the eukaryotic homolog eIF1 and the bacterial IF3 (Gualerzi et al. 2001; Kapp and Lorsch 2004; Passmore et al. 2007).

Another aspect of translation initiation that this study has taken into scrutiny is the mechanism and the order of events by which the Met-tRNAi ${ }^{\mathrm{Met}}$ is recruited by the ribosome during formation of the translation initiation complex in S. solfataricus. Formation of this complex is an essential step of protein synthesis in all domains of life, although the mechanism by which this occurs is different, at least in Bacteria and Eukarya. It is accepted that in Eukaryotes eIF2-GTP binds Met-tRNAi ${ }^{\text {Met }}$ in the cytoplasma and that it serves as a carrier to bring Met-tRNAi ${ }^{\text {Met }}$ to the ribosome (Kapp and Lorsch 2004). In contrast, recent data revealed that in Escherichia coli IF2 binds first to the $30 \mathrm{~S}$ subunit and then recruits $\mathrm{fMet}-\mathrm{tRNAi} \mathrm{i}_{\mathrm{f}}^{\mathrm{Met}}$
(M Carotti and CO Gualerzi, unpubl.). The situation in S. solfataricus is more complex, as a/eIF2 does not only bind to Met-tRNAi ${ }^{\mathrm{Met}}$ and to the $30 \mathrm{~S}$ subunit but also to the $5^{\prime}-\mathrm{P}_{3}$-end of mRNA, whereby binding to the latter serves to protect mRNAs from $5^{\prime} \rightarrow 3^{\prime}$ decay (Hasenöhrl et al. 2008). Surprisingly, our recent experiments revealed that the affinity of a/eIF2 for the $5^{\prime}-\mathrm{P}_{3}$-end of mRNA was one order of magnitude higher than for Met-tRNAi ${ }^{\text {Met }}$, indicating that-in contrast to Eukaryotes - an assembly of an a/eIF2-GTP•Met-tRNAi ${ }^{\text {Met }}$ complex is unlikely in the presence of competing $5^{\prime}-\mathrm{P}_{3}$ mRNA termini. However, the results of the FRET assays in which the $K_{\mathrm{d}}$ for all three ligands of a/eIF2, namely, the 30S.aIF1/1A complex (Fig. 3B), MettRNAi $^{\mathrm{Met}}$, and the $5^{\prime}$ - $\mathrm{P}_{3}$-end of mRNA (Fig. 4A) were determined, indicate that there is no competition between Met-tRNAi ${ }^{\mathrm{Met}}$ and the $5^{\prime}-\mathrm{P}_{3}$-end of mRNA when the MettRNAi ${ }^{\mathrm{Met}}$ is bound to a/eIF2 in a 30S•a/eIF2•aIF1•aIF1AGTP•Met-tRNAi ${ }^{\text {Met }}$ complex (Fig. 4B,C). The FRET-based calculation of the $K_{\mathrm{d}}$ 's of a/eIF2 for Met-tRNAi ${ }^{\text {Met }}$ and for the $5^{\prime}-\mathrm{P}_{3}$-end of mRNA are in the same range as determined recently using biochemical assays (Hasenöhrl et al. 2008).

Overall, our results indicate that the Met-tRNAi ${ }^{\mathrm{Met}}$ is not carried to the ribosomes by the initiation factor but is instead recruited at the ribosomal level. A working model for translation initiation in the crenarchaeon S. solfataricus is shown in Figure 5. Initially, aIF1 and aIF1A induce structural changes in the $30 \mathrm{~S}$ subunit, which facilitate binding of a/eIF2-GTP. As 30S-bound a/eIF2 has a negligible affinity for $5^{\prime}-\mathrm{P}_{3}$ RNA (Fig. 4B), Met-tRNAi ${ }^{\text {Met }}$ is recruited to the 30S•aIF1•aIF1A•a/eIF2-GTP complex. These FRET data would support our working model in that binding of a/eIF2 to the $5^{\prime}-\mathrm{P}_{3}$-end of mRNA, and thereby mRNA stabilization by a/eIF2, is only brought about under conditions when free $30 \mathrm{~S}$ ribosomes are limiting (Hasenöhrl et al. 2008). Clearly, the model shown in Figure 5 is based on $K_{\mathrm{d}}$ values derived from defined in vitro experiments. As the intracellular levels of the translational components are unknown in S. solfataricus, the working model cannot account for eventual fluctuations in the concentrations of translational components or that of mRNAs. Nonetheless, our recent data indicated that at least during mimicked starvation conditions a/eIF2 is in excess over ribosomes (Hasenöhrl et al. 2008). At least under such conditions the order of events shown in Figure 5 seems conceivable.

Like in Bacteria, a canonical mRNA containing a SD sequence can directly bind to $S$. solfataricus 30 S subunits through the SD-anti-SD interaction, whereas leaderless mRNAs, which depend on the start-codon/anti-codon interaction, require a P-site bound tRNAi (Grill et al. 2000; Moll et al. 2001; Benelli et al. 2003). As leaderless mRNAs are prevalent in Sulfolobus spp. (She et al. 2001), the postulated mechanism of translation initiation (Fig. 5), i.e., recruitment of Met-tRNAi ${ }^{\mathrm{Met}}$ by $30 \mathrm{~S}$-bound a/eIF2, 


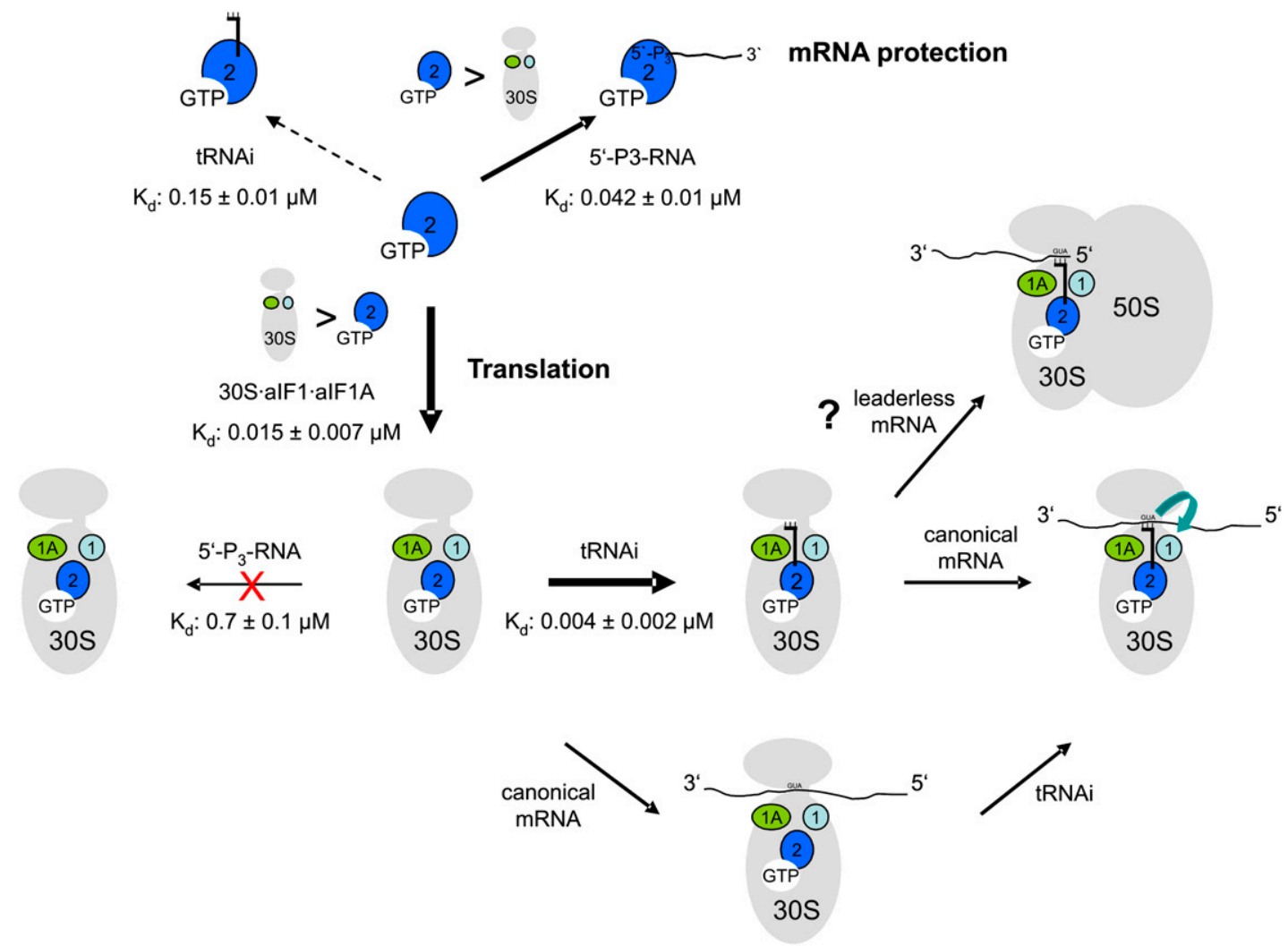

FIGURE 5. Model for the order of events of a/eIF2 binding to different ligands and the sequence of events in translation initiation. When ribosomes are limiting and the number of a/eIF2 molecules exceeds $(>)$ that of free $30 \mathrm{~S}$ ribosomes, the translation initiation factor may bind preferentially to the $5^{\prime}-\mathrm{P}_{3}$-end of mRNA, a situation that may occur during slow growth conditions (Hasenöhrl et al. 2008). In opposite, when the number of free ribosomes equals or exceeds $(>)$ that of a/eIF2, which may occur during fast growth, the factor binds to ribosomes. Our data revealed that a/eIF2 binding to $30 \mathrm{~S}$ subunits is accelerated by the aIF1 and aIF1A. Next, Met-tRNAi ${ }^{\mathrm{Met}}$ is recruited by a/eIF2 being part of the 30S•aIF1•aIF1A•a/eIF2-GTP complex. It remains to be shown whether canonical mRNAs are recruited to the initiation complex before or after Met-tRNAi ${ }^{\mathrm{Met}}$ binding. In the next step, the correct start-codon/anti-codon interaction is monitored by aIF1 (indicated by a blue arrow). We speculate that the Met-tRNAi ${ }^{\text {Met }}$ bound in the initiation complex is especially important for the recruitment of leaderless mRNAs. In analogy to E. coli (Moll et al. 2004), we consider that a leaderless mRNA is recruited to a $70 \mathrm{~S}$ initiation complex. The given $K_{\mathrm{d}}$ values were taken from Figures 3 and 4 .

could be of particular importance to accelerate translation of this class of mRNAs.

\section{MATERIALS AND METHODS}

\section{Preparation of $S$. solfataricus ribosomes, 2508sh RNA, Met-tRNAi ${ }^{\mathrm{Met}}$, and translation initiation factors}

S. solfataricus ribosomes were prepared from frozen cells as described before (Londei et al. 1986). 2508sh RNA with a triphosphate at the $5^{\prime}$-end $\left(5^{\prime}-\mathrm{P}_{3}\right)$ was prepared as described (Hasenöhrl et al. 2008). The 2508sh RNA corresponds in sequence to nucleotides 1-135 (5'-P - $_{3}$-ATGATTGTAGGATTTGCCGGAAA ACTATATAAAAACTATGAGAAAGATGGTATAGAGTTATTGA AAGAGGTCACTGATGAGGCACTAGATATTGCTGGATTGAAT TACGCTGACGTCGATGGGATAATGGCTAAC-3') of the bicistronic S. solfataricus 2508 mRNA (1507 nucleotides), encoding the leaderless acetyl-CoA-acetyltransferase (SSO2508) gene (the start codon is underlined) and a downstream gene coding for a predicted nucleic acid binding protein (SSO2509). E. coli tRNAi, which is functionally identical to that of $S$. solfataricus tRNAi (Yatime et al. 2004, 2006), was charged with methionine as described (Pedulla et al. 2005). The a/eIF2 subunits and N-terminal His-tagged aIF1 were prepared as described before (Pedulla et al. 2005; Hasenöhrl et al. 2006).

The gene encoding aIF1A was cloned by means of PCR amplification from $S$. solfataricus genomic DNA. The forward primer aIF1A_FP (5'-GTGTCAAAGGATCCTTGCCTAAGAAAG ATAGAGCGCAGG- $\left.3^{\prime}\right)$ and the reverse primer aIF1A_RP (5'-TT ATCCTCTTAACTGGTCAATTACTTCTAGGAATTCCGCGG CGC-3') were used for PCR. They contained restriction sites (underlined; BamHI and EcoRI) for insertion into the corresponding sites of the expression vector pRSETB (Invitrogen). The recombinant plasmid was sequenced and transformed into $E$. coli BL21(DE3) (Stratagene). The expression of aIF1A was induced for $3 \mathrm{~h}$ with $1 \mathrm{mM}$ IPTG at an $\mathrm{OD}_{600}$ of 0.5 . The cells were lysed and the cell extracts were heated for $10 \mathrm{~min}$ at $70^{\circ} \mathrm{C}$ and centrifuged at $10,000 \mathrm{~g}$ for $10 \mathrm{~min}$ to precipitate the $E$. coli proteins. The recombinant proteins, which contained an N-terminal tag of six histidines, were purified to homogeneity by affinity chromatography on Ni-NTA agarose following standard protocols (Qiagen). 
The purified proteins were dialyzed against storage buffer $(10 \mathrm{mM}$ MOPS, $200 \mathrm{mM} \mathrm{KCl}, 10 \mathrm{mM} \beta$-mercaptoethanol, and $10 \%$ glycerol) and stored at $80^{\circ} \mathrm{C}$ in aliquots.

\section{Hydroxyl radical probing with Fe(II)-EDTA}

The experiments were performed on a Bio-Logic SFM-400 fast mixing apparatus in quench flow mode as described by Fabbretti et al. (2007), which ensured a high reproducibility of the experiments. Ribosomes and aIF1 were in reaction buffer $(10 \mathrm{mM}$ $\mathrm{KCl}, 20 \mathrm{mM} \mathrm{Mg}[\mathrm{OAc}]_{2}, 20 \mathrm{mM}$ HEPES at $\left.\mathrm{pH} 7.1\right)$ and were preheated to $65^{\circ} \mathrm{C}$ for $5 \mathrm{~min}$ before use. Syringes 1 and 2 were filled with 2, 5, or $10 \mu \mathrm{M}$ aIF1 and $1 \mu \mathrm{M}$ S. solfataricus $30 \mathrm{~S}$ ribosomal subunits containing $0.45 \% \mathrm{H}_{2} \mathrm{O}_{2}$, respectively. Equal volumes $(20 \mu \mathrm{L})$ of the two solutions were rapidly mixed followed by a reaction time of $2 \mathrm{sec}$ before addition of $20 \mu \mathrm{L}$ of a freshly prepared $15 \mathrm{mM} \mathrm{Fe}(\mathrm{II})$-EDTA solution present in syringe 3 . The cleavage reaction was allowed to proceed for 20-30 msec before addition of $180 \mu \mathrm{L}$ of quenching solution $\left(100 \mathrm{mM} \mathrm{Na}[\mathrm{OAc}]_{2}\right.$ at $\mathrm{pH} 5.4$ in Ethanol) present in syringe 4.

The samples were subjected to primer extension reactions and sequenced by using twenty $5{ }^{\prime}-{ }^{32} \mathrm{P}$-labeled DNA oligonucleotides complementary spanning the $16 \mathrm{~S}$ rRNA. Primer extension was performed using AMV-RT (Promega). The polyacrylamide gels $(8 \%)$ were exposed and the bands were quantified using a Typhoon 8600 PhosphorImager and ImageQuant software (Amersham Bioscience), respectively.

\section{Preparation and activity of fluorescently labeled components}

AUG-mRNA (5'-GGCAGAGGUGAUAAAUACAUGUUCACGAU-3') and AUU-mRNA (5'-GGCAGAGGUGAUAAAUACAUUUUCAC GAU- $3^{\prime}$ ) oligos with $3^{\prime}$-end modification (FAM), termed AUGmRNA $_{F}$ and AUU-mRNA , were purchased from Microsynth (Switzerland). The SD-sequences $5^{\prime}$ of the AUG start codon (bold) and AUU codon (bold) are underlined. Equal labeling of both RNAs with FAM was verified by spectroscopic determination of the RNA concentration to FAM label ratio.

E. coli tRNAi ( $\mathrm{tRNA}_{\mathrm{f}}^{\mathrm{Met}}$ ) was labeled at a thiouridine at position 8 with 5-iodoacetamidofluorescein (Invitrogen) according to a recently published protocol (Milon et al. 2007). As determined by reverse phase HPCL, $100 \%$ of the tRNAi was labeled with the fluorophor. $\mathrm{tRNAi} \mathrm{i}_{\mathrm{F}}$ was then aminoacetylated as described above. The aminoacetylated and labeled tRNAi is referred to in the text as Met-tRNAi $\mathrm{M}_{\mathrm{F}}$. When compared to unlabeled $S$. solfataricus MettRNAi ${ }^{\mathrm{Met}}$, E. coli Met-tRNAi $\mathrm{M}_{\mathrm{F}}^{\mathrm{Met}}$ showed the same binding affinity to $S$. solfataricus a/eIF2•GTP in an in vitro filter binding assay (data not shown).

2508sh RNA was labeled (Milon et al. 2007) with fluorescein at the $3^{\prime}$ end to prevent interference with binding to a/eIF2 $\gamma$. Absorbance measurements showed that the extent of labeling was $>95 \%$. Binding of $2508 s h_{\mathrm{F}}$ RNA and 2508 sh RNA to a/eIF2 $\gamma$ was identical in a filter binding assay (data not shown).

A single cysteine was introduced into the $\alpha$-subunit of a/eIF2 as follows. The amino acid at position 11 (Glutamic Acid) was changed to a cysteine by means of PCR using aIF2_C11_FP (5' -TTTT TTCATATGATTTACAGTAGAAGCAAACTACCCTCATGCGGA GAAATTTTAATTGCAACTG-3') as forward and aIF2_C11_RP
(5' -TTTTTCTCGAGTTTCTTAACCACACTTATAT-3') as reverse primer. The oligonucleotides contained restriction sites (underlined; NdeI and Xhol) for insertion into the corresponding sites of the expression vector pET22b (Novagen). The mutant a/eIF2 $\alpha$-subunit gene was expressed and the corresponding protein was purified as specified above for aIF1A. The a/eIF2 $\alpha^{\mathrm{C} 11}$-subunit was labeled with the fluorescent dye Atto565 according to Milon et al. (2007). The abbreviation a/eIF2 ${ }_{565}$ is used for the reconstituted trimeric factor (Pedulla et al. 2005), consisting of the $\alpha^{\mathrm{C} 11}{ }_{565}, \beta$ - and $\gamma$-subunits. As the labeled protein showed reduced electrophoretioc mobility when compared with the unmodified one, the efficiency of modification was assessed by SDSPAGE (data not shown). Maximum modification (>95\%) was achieved after $1.5 \mathrm{~h}$ incubation of a/eIF2 $\alpha$ with Atto565 at room temperature. The activity of a/eIF2 ${ }_{565}$ in subunit formation and binding of Met-tRNAi ${ }^{\text {Met }}$ was identical to that of a/eIF2 as determined by native gel electrophoresis and filter binding assays (data not shown). The concentration of active a/eIF2 ${ }_{565}$ (see Figs. 3, 4) was determined by a titration filter binding assay using $\left[{ }^{35} \mathrm{~S}\right]$ Met-tRNAi ${ }^{\mathrm{Met}}$ (Smith 1998). This assay revealed that $>90 \%$ of a/eIF $2_{565}$ was active (data not shown). All labeled components were stable under the assay conditions used.

\section{Rapid kinetic measurements}

The measurements were carried out with a KinTec RQF-3 apparatus (KinTec). For a/eIF $2_{565}$ fluorescence excitation was at $565 \mathrm{~nm}$ and output was monitored using a KV600 nm long-pass filter. For the Met-tRNAi $\mathrm{M}_{\mathrm{F}}^{\mathrm{Met}}-\mathrm{a} / \mathrm{eIF} 2_{565}$ FRET, AUG-mRNA $\mathrm{F} / \mathrm{AUU}-$ mRNA $_{\mathrm{F}}-\mathrm{a} / \mathrm{eIF}{ }_{565}$ FRET, and 2508 sh $_{\mathrm{F}}$ RNA-a/eIF2 ${ }_{565}$ FRET experiments excitation was at $460 \mathrm{~nm}$ and output was monitored using a KV600 nm long-pass filter. All measurements were performed in $10 \mathrm{mM} \mathrm{KCl}, 20 \mathrm{mM} \mathrm{Mg}(\mathrm{OAc})_{2}, 20 \mathrm{mM}$ HEPES $(\mathrm{pH} 7.1)$ at $50^{\circ} \mathrm{C}$. All fluorescence and FRET experiments were carried out in triplicates with eight shots per experiment, and the traces presented are an average of three experiments. At least 500 time points occurred in the regions with fluorescence change in each experiment.

\section{Binding of a/elF2 to $30 \mathrm{~S}$ subunits}

All 30S-containing solutions were incubated for $10 \mathrm{~min}$ at $65^{\circ} \mathrm{C}$ before mixing with a/eIF $2_{565}$. The three subunits of a/eIF2 $\left(\alpha_{565}\right.$, $\beta$, and $\gamma$ ) were pre-incubated for $10 \mathrm{~min}$ at $65^{\circ} \mathrm{C}$ before they were added to the $30 \mathrm{~S}$ subunits. The final concentrations were $0.15 \mu \mathrm{M}$ a/eIF2 ${ }_{565}, 0.3 \mu \mathrm{M}$ 30S, $0.4 \mu \mathrm{M}$ aIF1, and $0.4 \mu \mathrm{M}$ aIF1A. The data were evaluated with Prism 4.03 (GraphPad Software Inc.) by fitting the two-exponential function $\mathrm{Y}=\mathrm{A}_{0}+\mathrm{A}_{1}{ }^{*} \exp \left(-k_{\mathrm{app} 1}{ }^{*} \mathrm{x}\right)+$ $\mathrm{A}_{2}{ }^{*} \exp \left(-k_{\mathrm{app} 2}{ }^{*} \mathrm{x}\right)$, with $k_{\mathrm{app} 1}$ and $k_{\mathrm{app} 2}$ and $\mathrm{A}_{1}$ and $\mathrm{A}_{2}$ as the apparent rate constants and the respective amplitudes. To determine average rate constants, $k_{\mathrm{av}}$, which are the inverse of the time at which a reaction reached $50 \%$ completion, all $k_{\text {app }}$ values and their respective amplitudes were taken into account. The weighted average was calculated as $k_{\mathrm{av}}=\left(k_{\mathrm{app} 1}{ }^{*} \mathrm{~A}_{1}+k_{\mathrm{app} 2}{ }^{*} \mathrm{~A}_{2}\right) /\left(\mathrm{A}_{1}+\mathrm{A}_{2}\right)$. To determine the association rate constant $\left(k_{\text {on }}\right)$ for a/eIF2 binding to the $30 \mathrm{~S}$ ribosomal subunit, the $k_{\text {app2 }}\left(=k_{\text {fast }}\right)$ values were determined as a function of a/eIF2 concentration. The values of the slope of the interpolated lines represent the $k_{\text {on }}$ of a/eIF2 binding to either $30 \mathrm{~S}$ ribosomal subunits or to a 30S•aIF1/1A complex. The $y$-axis intercept of the yielded dissociation rate 
constant was interpreted as the dissociation rate constant $k_{\text {off }}$ and used for the calculation of the equilibrium binding constant $K_{\mathrm{d}}$ using the equation $K_{\mathrm{d}}=k_{\text {off }} / k_{\text {on }}$.

\section{Binding of Met-tRNAi ${ }_{\mathrm{F}}^{\text {Met }}$ and $2508 s h_{\mathrm{F}}$ mRNA to a/elF2 $2_{565}$}

Binding of Met-tRNAi ${ }_{\mathrm{F}}^{\text {Met }}$ to a/eIF $2_{565}$ was monitored by FRET using fluorescein as fluorescence donor and Atto565 as acceptor. The three subunits of a/eIF2 $\left(\alpha_{565}, \beta\right.$, and $\left.\gamma\right)$ were incubated for $10 \mathrm{~min}$ at $65^{\circ} \mathrm{C}$ with or without GTP before they were incubated with 30 S subunits, and/or $5^{\prime}-\mathrm{P}_{3}$ (triphosphorylated) 2508 sh $h_{\mathrm{F}} \mathrm{RNA}$, and Met-tRNAi $\mathrm{i}_{\mathrm{F}}^{\mathrm{Met}}$, respectively. The $30 \mathrm{~S}$ subunits were incubated for $10 \mathrm{~min}$ at $65^{\circ} \mathrm{C}$ before they were mixed with a/eIF2 ${ }_{565}$. The final concentrations were $0.15 \mu \mathrm{M}$ a/eIF $2_{565}, 10 \mu \mathrm{M}$ GTP, $0.3 \mu \mathrm{M}$ Met-tRNAi $\mathrm{Met}_{\mathrm{F}}, \quad 0.3 \mu \mathrm{M}$ 30S, and $0.3 \mu \mathrm{M}$ 2508sh $h_{\mathrm{F}}$ RNA. Data were evaluated by fitting the two-exponential function $\mathrm{Y}=$ $\mathrm{A}_{0}+\mathrm{A}_{1}{ }^{*} \exp \left(-k_{1}{ }^{*} \mathrm{x}\right)+\mathrm{A}_{2}{ }^{*} \exp \left(-k_{2}{ }^{*} \mathrm{x}\right)$. To determine the $k_{\text {on }}$ for Met-tRNAi Met and $2508 s h_{\mathrm{F}}$ RNA binding to a/eIF2-GTP, the $k_{\text {app }}$ values were determined as a function of the a/eIF $2_{565}$ concentration $(0.05 ; 0.1 ; 0.2$; and $0.3 \mu \mathrm{M})$. The value of the slope of the interpolated line represents the $k_{\text {on }}$ of Met-tRNAi Met and $2508 s h_{\mathrm{F}}$ binding to a/eIF2 ${ }_{565}$. The $y$-axis intercept of the yielded dissociation rate constant was interpreted as the dissociation rate constant $k_{\text {off }}$ and used for the calculation of the equilibrium binding constant $K_{\mathrm{d}}$.

\section{Binding of AUG-mRNA $F$ and AUU-mRNA $F$ to $30 S$ ribosomal subunits}

Binding of AUG-mRNAF or AUU-mRNAF to $30 \mathrm{~S} \bullet \mathrm{a} / \mathrm{eIF} 2_{565^{-}}$ $\mathrm{GTP} \bullet$ Met-tRNAi ${ }^{\mathrm{Met}} \bullet \mathrm{aIF} 1 \mathrm{~A} \bullet(\mathrm{aIF} 1)$ complexes was monitored by FRET, whereby $\mathrm{mRNA}_{\mathrm{F}}$ was used as fluorescence donor and a/eIF $2_{565}$ as acceptor. The three subunits of a/eIF2 $\left(\alpha_{565}, \beta\right.$, and $\left.\gamma\right)$ were incubated for $10 \mathrm{~min}$ at $65^{\circ} \mathrm{C}$ with GTP. The a/eIF2 ${ }_{565}$-GTP complex was added to preformed 30S•aIF1A or 30S•aIF1/1A complexes and incubated for $5 \mathrm{~min}$ at $65^{\circ} \mathrm{C}$ before Met-tRNAi ${ }^{\mathrm{Met}}$ was added, and the incubation time was extended for $5 \mathrm{~min}$ at $65^{\circ} \mathrm{C}$. The $30 \mathrm{~S} \bullet$ a/eIF ${ }_{565}-\mathrm{GTP} \bullet$ Met-tRNAi ${ }^{\mathrm{Met}} \bullet \mathrm{aIF} 1 \mathrm{~A} \bullet(\mathrm{aIF} 1)$ complex was then mixed with $\mathrm{mRNA}_{\mathrm{F}}$ in the KinTec apparatus. The final concentrations were $0.15 \mu \mathrm{M}$ a/eIF2 $2_{565}, 10 \mu \mathrm{M}$ GTP, $0.2 \mu \mathrm{M}$ MettRNAi $^{\mathrm{Met}}, 0.3 \mu \mathrm{M}$ 30S, $0.45 \mu \mathrm{M}$ aIF1, $0.45 \mu \mathrm{M}$ aIF1A, and $0.2 \mu \mathrm{M}$ AUG-mRNA $A_{F}$ or AUU-mRNAF. Data were evaluated by fitting the two-exponential function $\mathrm{Y}=\mathrm{A}_{0}+\mathrm{A}_{1}{ }^{*} \exp \left(-k_{1}{ }^{*} \mathrm{x}\right)+\mathrm{A}_{2}{ }^{*} \exp \left(-k_{2}{ }^{*} \mathrm{x}\right)$. The weighted average was calculated as $k_{\mathrm{av}}=\left(k_{\mathrm{app} 1}{ }^{\star} \mathrm{A}_{1}+\right.$ $\left.k_{\text {app2 }}{ }^{*} \mathrm{~A}_{2}\right) /\left(\mathrm{A}_{1}+\mathrm{A}_{2}\right)$, where $k_{\text {app } 1}$ and $k_{\text {app2 }}$ and $\mathrm{A}_{1}$ and $\mathrm{A}_{2}$ are the apparent rate constants and the respective amplitudes estimated from two-exponential fitting of the time courses.

\section{SUPPLEMENTAL MATERIAL}

Supplemental material can be found at http://www.rnajournal.org.

\section{ACKNOWLEDGMENTS}

The work was supported by the MIUR grants PRIN 2007 to P.L. and C.O.G. and by grants J2627 (D.H.) and P15334 (U.B.) from the Austrian Science Fund (FWF).

Received March 26, 2009; accepted September 9, 2009.

\section{REFERENCES}

Acker MG, Lorsch JR. 2008. Mechanism of ribosomal subunit joining during eukaryotic translation initiation. Biochem Soc Trans 36: 653-657.

Benelli D, Maone E, Londei P. 2003. Two different mechanisms for ribosome/mRNA interaction in archaeal translation initiation. Mol Microbiol 50: 635-643.

Boelens R, Gualerzi CO. 2002. Structure and function of bacterial initiation factors. Curr Protein Pept Sci 3: 107-119.

Carter AP, Clemons WMJ, Brodersen DE, Morgan-Warren RJ, Hartsch T, Wimberly BT, Ramakrishnan V. 2001. Crystal structure of an initiation factor bound to the $30 \mathrm{~S}$ ribosomal subunit. Science 291: 498-501.

Cheung YN, Maag D, Mitchell SF, Fekete CA, Algire MA, Takacs JE, Shirokikh N, Pestova T, Lorsch JR, Hinnebusch AG. 2007. Dissociation of eIF1 from the $40 \mathrm{~S}$ ribosomal subunit is a key step in start codon selection in vivo. Genes \& Dev 21: 1217-1230.

Dallas A, Noller HF. 2001. Interaction of translation initiation factor 3 with the 30S ribosomal subunit. Mol Cell 8: 855-864.

Fabbretti A, Milon P, Giuliodori A, Gualerzi CO, Pon CL. 2007. Realtime dynamics of ribosome-ligand interaction by time-resolved chemical probing methods. Methods Enzymol 430: 45-58.

Fraser CS, Berry KE, Hershey JW, Doudna JA. 2007. eIF3j is located in the decoding center of the human $40 \mathrm{~S}$ ribosomal subunit. Mol Cell 26: $811-819$.

Grill S, Gualerzi CO, Londei P, Bläsi U. 2000. Selective stimulation of translation of leaderless mRNA by initiation factor 2: Evolutionary implications for translation. EMBO J 19: 4101-4110.

Gualerzi CO, Pon CL. 1990. Initiation of mRNA translation in Prokaryotes. Biochemistry 29: 5881-5889.

Gualerzi CO, Brandi L, Caserta E, Garofalo C, Lammi M, La Teana A, Petrelli D, Spurio R, Tomsic J, Pon CL. 2001. Initiation factors in the early events of mRNA translation in bacteria. Cold Spring Harb Symp Quant Biol 66: 363-376.

Hartz D, Binkley J, Hollingsworth T, Gold L. 1990. Domains of initiator tRNA and initiation codon crucial for initiator tRNA selection by Escherichia coli IF3. Genes \& Dev 4: 1790-1800.

Hasenöhrl D, Benelli D, Barbazza A, Londei P, Bläsi U. 2006. Sulfolobus solfataricus translation initiation factor 1 stimulates translation initiation complex formation. RNA 12: 674-682.

Hasenöhrl D, Lombo T, Kaberdin V, Londei P, Bläsi U. 2008. Translation initiation factor a/eIF2 $(-\gamma)$ counteracts $5^{\prime}$ to $3^{\prime}$ mRNA decay in the archaeon Sulfolobus solfataricus. Proc Natl Acad Sci 105: 2146-2150.

Kaminishi T, Wilson DN, Takemoto C, Harms JM, Kawazoe M, Schluenzen F, Hanawa-Suetsugu K, Shirouzu M, Fucini P, Yokoyama S. 2007. A snapshot of the 30 S ribosomal subunit capturing mRNA via the Shine-Dalgarno interaction. Structure 15: 289-297.

Kapp LD, Lorsch JR. 2004. The molecular mechanics of eukaryotic translation. Annu Rev Biochem 73: 657-704.

La Teana A, Gualerzi CO, Brimacombe R. 1995. From stand-by to decoding site. Adjustment of the mRNA on the $30 \mathrm{~S}$ ribosomal subunit under the influence of the initiation factors. RNA 1: 772782.

Laursen BS, Sorensen HP, Mortensen KK, Sperling-Petersen HU. 2005. Initiation of protein synthesis in bacteria. Microbiol Mol Biol Rev 69: 101-123.

Lomakin IB, Kolupaeva VG, Marintchev A, Wagner G, Pestova TV. 2003. Position of eukaryotic initiation factor eIF1 on the $40 \mathrm{~S}$ ribosomal subunit determined by directed hydroxyl radical probing. Genes \& Dev 17: 2786-2797.

Londei P, Altamura S, Cammarano P, Petrucci L. 1986. Differential features of ribosomes and of poly(U)-programmed cell-free systems derived from sulphur-dependent archaebacterial species. Eur J Biochem 157: 455-462.

Maag D, Fekete CA, Gryczynski Z, Lorsch JR. 2005. A conformational change in the eukaryotic translation preinitiation complex and 
release of eIF1 signal recognition of the start codon. Mol Cell 17: 265-275.

Maag D, Algire MA, Lorsch JR. 2006. Communication between eukaryotic translation initiation factors 5 and $1 \mathrm{~A}$ within the ribosomal pre-initiation complex plays a role in start site selection. J Mol Biol 356: 724-737.

Maone E, Di Stefano M, Berardi A, Benelli D, Marzi S, La Teana A, Londei P. 2007. Functional analysis of the translation factor aIF2/5B in the thermophilic archaeon Sulfolobus solfataricus. Mol Microbiol 65: 700-713.

Marzi S, Knight W, Brandi L, Caserta E, Soboleva N, Hill WE, Gualerzi CO, Lodmell JS. 2003. Ribosomal localization of translation initiation factor IF2. RNA 9: 958-969.

Mayer C, Köhrer C, Kenny E, Prusko C, RajBhandary UL. 2003. Anticodon sequence mutants of Escherichia coli initiator tRNA: Effects of overproduction of aminoacyl-tRNA synthetases, methionyl-tRNA formyltransferase, and initiation factor 2 on activity in initiation. Biochemistry 42: 4787-4799.

McCutcheon JP, Agrawal RK, Philips SM, Grassucci RA, Gerchman SE, Clemons WM Jr, Ramakrishnan V, Frank J. 1999. Location of translational initiation factor IF3 on the small ribosomal subunit. Proc Natl Acad Sci 96: 4301-4306.

Milon P, Konevega AL, Peske F, Fabbretti A, Gualerzi CO, Rodnina MV. 2007. Transient kinetics, fluorescence, and FRET in studies of initiation of translation in bacteria. Methods Enzymol 430: 1-30.

Milon P, Konevega AL, Gualerzi CO, Rodnina MV. 2008. Kinetic checkpoint at a late step in translation initiation. Mol Cell 30: 712-720.

Moazed D, Samaha RR, Gualerzi CO, Noller HF. 1995. Specific protection of $16 \mathrm{~S}$ rRNA by translational initiation factors. $J \mathrm{Mol}$ Biol 248: 207-210.

Moll I, Huber M, Grill S, Sairafi P, Mueller F, Brimacombe R, Londei P, Bläsi U. 2001. Evidence against an Interaction between the mRNA downstream box and 16S rRNA in translation initiation. J Bacteriol 183: 3499-3505.

Moll I, Hirokawa G, Kiel MC, Kaji A, Bläsi U. 2004. Translation initiation with $70 \mathrm{~S}$ ribosomes: An alternative pathway for leaderless mRNAs. Nucleic Acids Res 32: 3354-3363.

Nikonov O, Stolboushkina E, Nikulin A, Hasenohrl D, Bläsi U, Manstein DJ, Fedorov R, Garber M, Nikonov S. 2007. New insights into the interactions of the translation initiation factor 2 from Archaea with guanine nucleotides and initiator tRNA. $J \mathrm{Mol}$ Biol 373: 328-336.

Passmore LA, Schmeing TM, Maag D, Applefield DJ, Acker MG, Algire MA, Lorsch JR, Ramakrishnan V. 2007. The eukaryotic translation initiation factors eIF1 and eIF1A induce an open conformation of the 40S ribosome. Mol Cell 26: 41-50.

Pedulla N, Palermo R, Hasenöhrl D, Bläsi U, Cammarano P, Londei P. 2005. The archaeal eIF2 homologue: Functional properties of an ancient translation initiation factor. Nucleic Acids Res 33: $1804-1812$.

Pestova TV, Lomakin IB, Lee JH, Choi SK, Dever TE, Hellen CU. 2000. The joining of ribosomal subunits in eukaryotes requires eIF5B. Nature 403: 332-335.
Petrelli D, LaTeana A, Garofalo C, Spurio R, Pon CL, Gualerzi CO. 2001. Translation initiation factor IF3: Two domains, five functions, one mechanism? EMBO J 20: 4560-4569.

Richter D, Lipmann F. 1970. Formation of a ternary complex between formylatable yeast Met-tRNA, GTP and binding factor T of yeast and of E. coli. Nature 227: 1212-1214.

She Q, Singh RK, Confalonieri F, Zivanovic Y, Allard G, Awayez MJ, Chan-Weiher CC, Clausen IG, Curtis BA, De Moors A, et al. 2001. The complete genome of the crenarchaeon Sulfolobus solfataricus P2. Proc Natl Acad Sci 98: 7835-7840.

Shin BS, Maag D, Roll-Mecak A, Arefin MS, Burley SK, Lorsch JR, Dever TE. 2002. Uncoupling of initiation factor eIF5B/IF2 GTPase and translational activities by mutations that lower ribosome affinity. Cell 111: 1015-1025.

Singh CR, He H, Ii M, Yamamoto Y, Asano K. 2004. Efficient incorporation of eukaryotic initiation factor 1 into the multifactor complex is critical for formation of functional ribosomal preinitiation complexes in vivo. J Biol Chem 279: 31910-31920.

Smith CWJ. 1998. RNA:protein interactions: A practical approach. Oxford University Press, Oxford, New York.

Sonenberg N, Hinnebusch AG. 2009. Regulation of translation initiation in eukaryotes: Mechanisms and biological targets. Cell 136: $731-745$.

Spahn CM, Beckmann R, Eswar N, Penczek PA, Sali A, Blobel G, Frank J. 2001. Structure of the 80 S ribosome from Saccharomyces cerevisiae-tRNA-ribosome and subunit-subunit interactions. Cell 107: 373-386.

Subramanian AR, Davis BD. 1970. Activity of initiation factor F3 in dissociating Escherichia coli ribosomes. Nature 228: 12731275.

Tolstrup N, Sensen CW, Garrett RA, Clausen IG. 2000. Two different and highly organized mechanisms of translation initiation in the archaeon Sulfolobus solfataricus. Extremophiles 4: 175-179.

Unbehaun A, Marintchev A, Lomakin IB, Didenko T, Wagner G, Hellen CU, Pestova TV. 2007. Position of eukaryotic initiation factor eIF5B on the $80 \mathrm{~S}$ ribosome mapped by directed hydroxyl radical probing. EMBO J 26: 3109-3123.

Yatime L, Schmitt E, Blanquet S, Mechulam Y. 2004. Functional molecular mapping of archaeal translation initiation factor 2. J Biol Chem 279: 15984-15993.

Yatime L, Mechulam Y, Blanquet S, Schmitt E. 2006. Structural switch of the $\gamma$ subunit in an archaeal aIF2 $\alpha \gamma$ heterodimer. Structure 14: $119-128$.

Yatime L, Mechulam Y, Blanquet S, Schmitt E. 2007. Structure of an archaeal heterotrimeric initiation factor 2 reveals a nucleotide state between the GTP and the GDP states. Proc Natl Acad Sci 104: 18445-18450.

Yusupov MM, Yusupova GZ, Baucom A, Lieberman K, Earnest TN, Cate JH, Noller HF. 2001. Crystal structure of the ribosome at 5.5 A resolution. Science 292: 883-896.

Yusupova G, Jenner L, Rees B, Moras D, Yusupov M. 2006. Structural basis for messenger RNA movement on the ribosome. Nature 444: 391-394. 

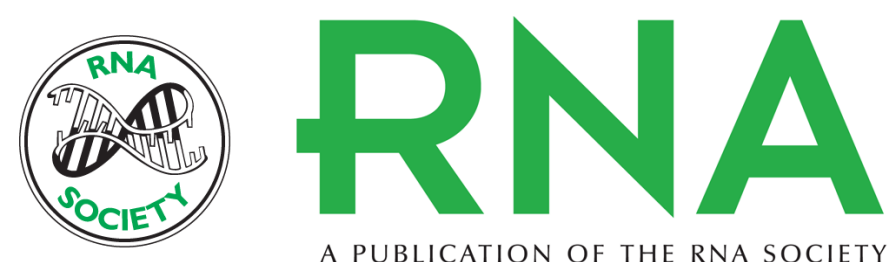

A PUBLICATION OF THE RNA SOCIETY

\section{Translation initiation complex formation in the crenarchaeon Sulfolobus solfataricus}

David Hasenöhrl, Attilio Fabbretti, Paola Londei, et al.

RNA 2009 15: 2288-2298 originally published online October 27, 2009

Access the most recent version at doi:10.1261/rna.1662609

\section{Supplemental http://rnajournal.cshlp.org/content/suppl/2009/10/23/rna.1662609.DC1 \\ Material}

References This article cites 50 articles, 19 of which can be accessed free at:

http://rnajournal.cshlp.org/content/15/12/2288.full.html\#ref-list-1

\section{License}

Email Alerting Receive free email alerts when new articles cite this article - sign up in the box at the Service top right corner of the article or click here. 